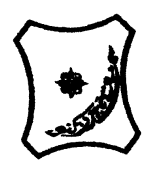

Bayero Journal of Pure and Applied Sciences, 12(1): 97 - 105

Received: December, 2018

Accepted: June, 2019

ISSN $2006-6996$

\title{
AN OVERVIEW OF THE MOST COMMON FOODBORNE PARASITIC INFECTIONS
}

Ismail, B. B, Mohammed, M*, Yusuf, H. L, and Sulaiman, S A.

Food Science and Technology Department, Bayero University Kano, Nigeria

*Correspondence author: linkmat2007@yahoo.com, Mobile, +2348036094471

\section{ABSTRACT}

Parasitic infections have and will continue to be the frequent cause of mortality and morbidity unless strict measures are put in place. The increase in international travels and globalization of food supply present an interesting trend in the cases of parasitic infections. Parasitic foodborne infections can be transmitted from one host to the other. The route of infection could either be waterborne, foodborne or through the fecal-oral route. They have been regarded as Neglected Tropical Diseases (NTDs) causing illness to more than one billion people globally but were given little attention by the public health community. This review will look at some of the most commonly reported foodborne parasitic infections and give a highlight on their sources, occurrence in foods, mode of transmission and control measures needed to mitigate their risks.

Keywords: Fecal-oral route,foods,food safety, Neglected Tropical Diseases, parasitic infections.

\section{INTRODUCTION}

Parasites are organisms which derive nourishment and protection by living on or in a hostand receiving food from or at the expense of its host (CDC, 2018; USDA, 2017). Parasitic foodborne infections can be transmitted from one host to the other. The route of infection could either be waterborne, foodborne or through fecal-oral route. They had been regarded as Neglected Tropical Diseases (NTDs), causing illness to more than one billion people globally but were given little attention by the public health community (CDC, 2018). The impact of the diseases apart from its negative effect on health, is that they contribute to an unending poverty cycle and stigma, making people incapable to work, go to school or partake in family and community life [WHO, 2010; The European Foundations Initiative for African Research into Neglected Tropical Diseases (2013)]. Some examples of these diseases include Guinea worm disease and lymphatic filariasis which affects the poor communities that do not have potable water to drink (WHO, 2010).

There had been a consistent report of parasitic infections in developing and endemic countries for many years. However, in the last two decades; the occurrence of parasitic infections in the developed countries had increased tremendously. In the US, for example, there had been a massive increase of outbreaks of parasitic foodborne infections during the past 15 years (Ortega, 2006). In the EU, over 2,500 cases of human parasitic food-borne infection are being reported each year (EFSA, 2017).

There are many factors associated with the increase in parasitic foodborne infections in the developed countries. Chief among these factors is the rapid propagation of parasitic diseases due to increasing international travels and migration of people within the continents. New challenges were also attributed tothe globalization of food supply. Food habits are alsochanging rapidly, which resultsin the consumption of fresh foods and vegetables. This makes it necessary to import foods so as to meet the consumer needs, and a whole year round supply of certain commodities, such as exotic fruits and vegetables. Unfortunately, the transportation conditions used such as controlled refrigeration are favourable for the growth and survival of parasites in foods (Ortega, 2006; Robertson, 2007). Other risk factors include an increase in vulnerable groups who are susceptible to illness, as well as, lack of improvement in communication and diagnostic tools (Dorny, et al., 2009).

This review will look at some of the emerging parasites such as Toxoplasmagondii (protozoan) and Trichinella (protozoan) which are widespread in the world and causes significant incidents of foodborne illnesses. To understand these organisms better, the review will cover aspects which include, nature of the organisms, occurrence in foods, symptoms, incidence, and outbreaks, stability in foods, as well as, some aspects of the control measures and treatment. 


\section{Toxoplasma gondii}

Toxoplasmagondibelongs to the coccidian family, and it has been reported to be the most common and widespread parasite in the world.It is responsible for $20.7 \%$ of the food-borne deaths due to identified infectious agents (Dorny, et al., 2009). Toxoplasmosis, an infection caused by Toxoplasma gondii can be asymptomatic and can lead to abortion in humans when an acute infection develops during pregnancy. This infection is prevalent in warm and humid climates (Bojar and
Szymanska, 2010). Toxoplasmosis is still been perceived as a neglected and under-reported disease, in spite of its disease burden akin to that of Salmonellosis and Campylobacteriosis (Kijlstra and Jongert, 2009). Figure 1 shows a typical picture of Toxoplasmagondii. Toxoplasmosisis also a major opportunistic infection inimmunodeficiency conditions such as AIDS and organ transplant patients (Saadatnia and

Golkar, 2012).

\section{Toxoplasma gondii}

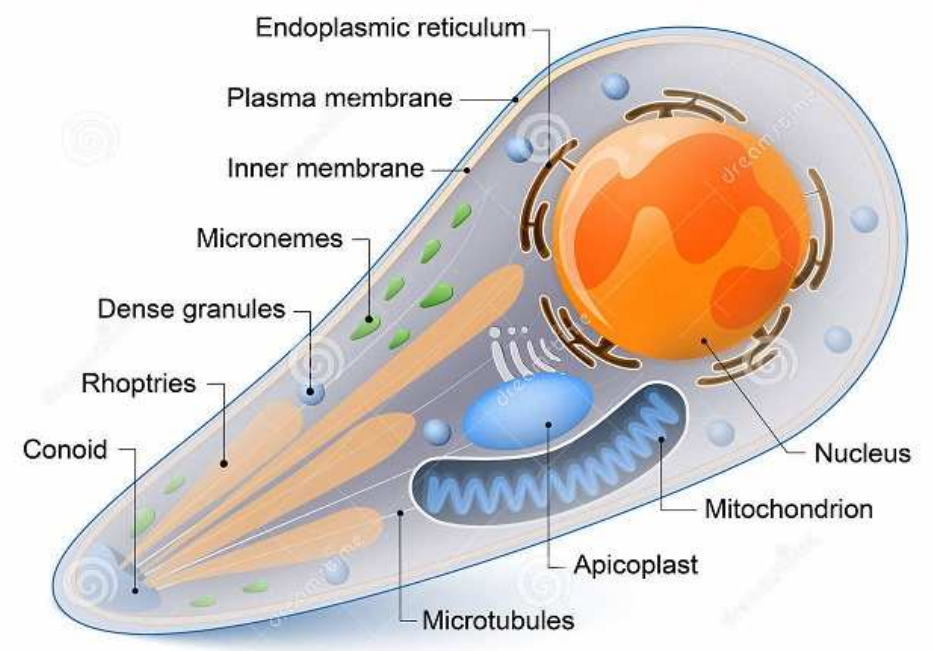

Figure 1: Toxoplasmagondii

Source:https://www.vectorstock.com/royalty-free-vector/toxoplasma-gondii-vector-11563382

As high as $85 \%$ of the population in some European countries were said to be identified with this parasite, and it has been associated with areas where meat is primarily eaten undercooked (Han,et al., 2008). Members of the cat family which includes domestic cats have been recognized as the definitive host of this obligate parasite. It exists in the faeces of cats and becomes transmittable following sporulation in the environment as part of its life cycle (Lawley, et al., 2012).

\section{Occurrence in Foods}

Epidemiological studies conducted indicated that Toxoplasma oocysts (a thick-walled structure in which sporozoan zygotes grow and which serves to transfer them into new hosts) may be present on raw foods contaminated by cat faeces (Cavalcante, et al.,2006; Dorny, et al., 2009; Liu, et al., 2009). Contaminated water has also been identified as a source of infection and it has been suggested that shellfish may retain these oocysts during growth in contaminated seawater (Lawley, et al., 2012).

The presence of tissue cysts in meat is perhaps of more importance from a food safety point of view, especially where undercooked meat is consumed in the Asian and Western countries. Toxoplasma cysts have been found in a variety of different domestic and wild cat species. However, infected pork is considered to be predominantly significant in the transmission of toxoplasmosis to humans. Toxoplasma is not typically associated with cooked and processed foods as the oocysts can be destroyed by heat (Tenter, et al., 2000; Lawley, et al., 2012). More illustration on the means of transmission is presented in Figure 2. 
BAJOPAS Volume 12 Number 1, June, 2019

Route of transmission of Toxoplasma gondif

Toxoplasma can be found in most species of wild birds although seroprevalence and frequency of parasite isolation vary between studies (Dorny, etal., 2009). The main routes of transmission of the oocysts as shown in Figure 2 are from animal to human (zoonotic), either through ingestion of oocysts by direct contact with cat faeces, contaminated food or water, or by ingestion of oocysts in raw or undercooked meat from an infected animal or through the environment. The direct person-to-person transmission has not been reported (Dorny, et al., 2009; Lawley, et al., 2012).

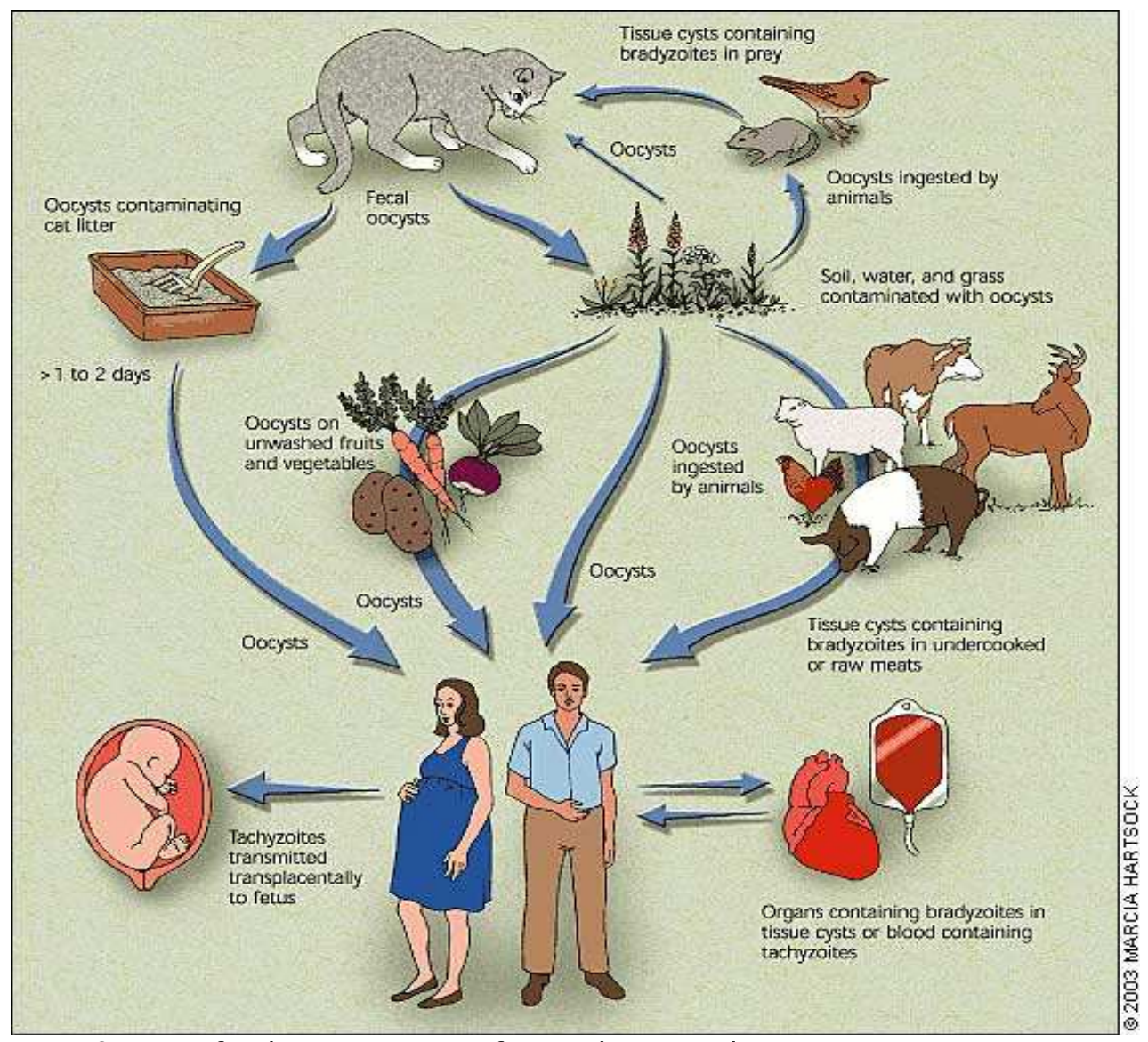

Figure 2: Route for the transmission of Toxoplasmagondii

Source: (Jeffrey Jones, et al., 2003).

\section{Symptoms}

Toxoplasmosis is mainly considered as a serious health problem in immunocompromised people and in pregnant women, who can potentially transmit the infection to the foetus or new-born (Kijlstra and Jongert, 2009). Symptoms due to congenital toxoplasmosis include visual impairment or blindness after birth, mental retardation, convulsions, and hydrocephalus in few cases (Antoniou, et al., 2007; Lawley, et al., 2012). Toxoplasma gondii infection in humans is said to be very common but is usually asymptomatic in many cases. Often ingestion of sporulatedoocysts into the host, it migrates through the body and invadesmany tissues. However no symptoms are usually perceived by the host, nonetheless, in nearly $15 \%$ of the reported cases, self-limiting mild flu-like symptoms, as well as swelling of the lymph nodes follows the invasion of the tissues. Additionally, in very rare cases as for immunocompromised individuals, more serious symptoms may develop, which include visual impairment and brain damage which could sometimes prove to be fatal. Where symptoms occur, the incubation time is usually from 3-25 days (Lawley, et al., 2012).

\section{Incidence and outbreaks}

Toxoplasma gondii is reported to be among the most common parasitic infections in humans, and at least one-third of the world's population were estimated to have been exposed to this parasite mostly through the food chain (Lawley, et al., 2012). 
BAJOPAS Volume 12 Number 1, June, 2019

In the UK, about $34 \%$ of adults are estimated to carry antibodies to Toxoplasma gondii, and 50$80 \%$ estimated from other EU countries, with overall 1788 cases reported in 2008 (Lawley, et al., 2012). The number of reported food-borne cases is probably higher in countries where raw and rare-cooked meats are a regular part of the diet. However, it is highly likely that there is a substantial under-reporting of the disease due to asymptomatic cases (Lawley, et al., 2012). Estimated incidences of acute toxoplasmosis in the USA suggested that as much as 1.5 million people suffer symptoms annually with a range of 400 and 4000 cases of congenital toxoplasmosis(CDC, 2018). Toxoplasmosis has been reported to be the third leading cause of food-borne related deaths in the US (Ortega, 2006).From 1998 through 2006, 44 cases occurred in French Guiana, a French territory in South America, all patients were immunocompetent (not HIV-infected) adults who had been hospitalized because of a marked, nonspecific, infectious syndrome (Carme, Demar, Ajzenberg, and Dardé, 2009).

\section{Stability in Foods and control measures}

Oocysts of Toxoplasma gondii are quite resistant to most environmental factors and can remain infectious for about 400 days in water. It is quite resistant to some sanitizers and disinfectants and may not be inactivated by the level of chlorine used in potable water treatment (Lawley, et al., 2012). However, it can be inactivated by drying and freezing at a temperature below $10^{\circ} \mathrm{C}$ and are not usually heat resistant and can,therefore, be destroyed by conventional pasteurization as in the case of milk (Lawley, et al., 2012; Dorny, et al., 2009). Good hygienic practices in meat production can be used to control the spread of the parasite in meat (Lawley, et al., 2012).

\section{Treatment}

Toxoplasmosis can be treated with a combination of antibiotics, but they can only suppress actively dividing parasites [Center for Food Security an Public Health and Institute for International Cooperation in Animal Biologics(CSFPH and IICAB, 2017)]. Furthermore, few certain drugs, such as clindamycin, trimethoprim-sulfonamide, azithromycin, andpyrimethamine, used alone or in various combinations, are effective. There is no effective human vaccine to protect against toxoplasma infection nor is there likely to be one in the near future (Liu, et al., 2012). A live attenuated vaccine, Toxovax $\AA$ (Intervet Schering Plough, Boxmeer, The Netherlands), is currently used in sheep to prevent abortion induced by congenital infection, but such a vaccine is not suitable for human use mainly because of the potential risk of reactivation to the pathogenic form (Saadatnia and Golkar, 2012). Dubey (1997) demonstrated that a $6 \%$ sodium chloride (SC) solution was lethal to isolated tissue cysts of Toxoplasmagondii. If one is infected during pregnancy, the mother and the baby should be closely monitored during pregnancy and after the baby is born. Persons with compromised immune systems, like AIDS patients, might need medication for the rest of their lives or for as long as they are immunosuppressed (WHO, 2015).

Table 1.Specific hygienic and dietary recommendations for pregnant women to avoid primary $T$. gondii infection

- Wear gloves and thoroughly clean hands and nails when handling material potentially contaminated by cat faeces (sand, soil, and gardening).

- Reduce the exposure risk of pet cats by (1) keeping all cats indoors (2) giving domestic cats only cooked, preserved, or dry food.

- Change litter and get rid of cat faeces (wearing gloves) on a regular basis (every 24 hours).

- Disinfect emptied cat litter tray with near-boiling water for 5 minutes before refilling.

- Eat only well-cooked meat $\left(>67^{\circ} \mathrm{C} / 153^{\circ} \mathrm{F}\right)$. - Freezing meat to at least $-20^{\circ} \mathrm{C} /-4^{\circ} \mathrm{F}$ also kills $\mathrm{T}$. gondii cysts.

- Clean surfaces and utensils that have been in contact with raw meat.

- Do not consume raw eggs or raw milk.

- Wash uncooked fruits and vegetables before consumption.

- Prevent cross-contamination: thoroughly clean hands and utensils after touching raw meat or vegetables.

- Do not drink water potentially contaminated with oocysts.

- Be aware that;

1. the process of curing, smoking, or drying meat does not necessary result in a product free of parasite cysts,

2. Refrigeration does not destroy the parasite (still viable after 68 days at $+4^{\circ} \mathrm{C}$ ). -

3. Microwave oven cooking does not destroy parasites.

Source: (Boucher, et al., 2013) 
BAJOPAS Volume 12 Number 1, June, 2019

\section{Trichinella species}

These are nematodes belonging to the genus Trichinella and are one of the most prevalent zoonotic pathogens globally. Trichinella species had been found worldwide and are reported to infect domestic and wild animals (both carnivorous and omnivorous) particularly scavengers such as bears, wild boar, pigs and foxes and can serve as a means of transmission in humans (Pozio and Murrell, 2006; Lawley, et al., 2012). One specieis also known to infect birds and a new genotype has been detected in crocodiles in Africa (Pozio, 2007). Figure 3 shows a partial coil of the Trichinella larva.

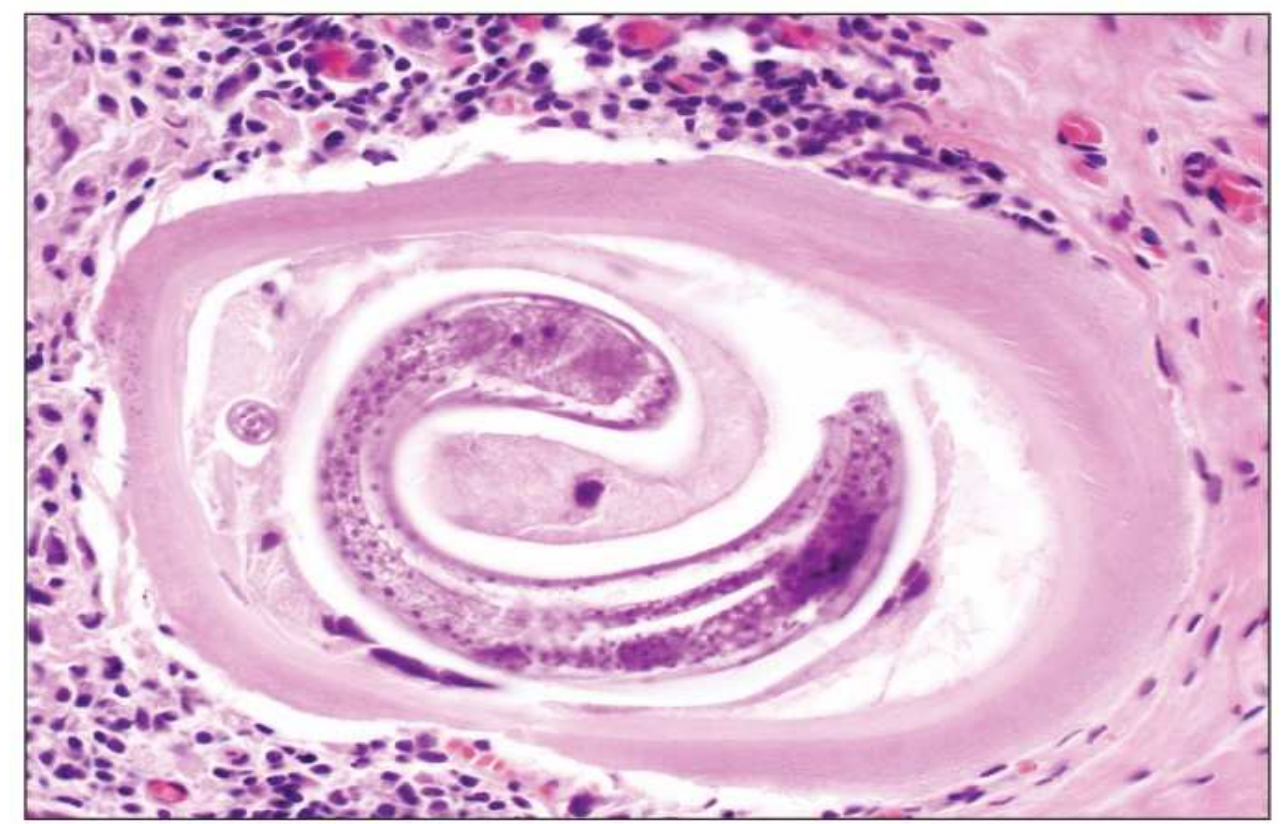

Figure 3: A partial coil of a Trichinella larva.

Source:(https://www.google.com.ng/search?q=partial+coil+of+trichinella+larva\&tbm=isch\&tbo=u\&s ource $=$ univ\&sa $=$ X\&ved $=0$ ahUKEwjx7t7jnJnaAhUC3iwKHUONAmgQsAQIJA\&biw $=1368 \&$ bih $=650 \#$ imgr $\underline{\mathrm{c}=\mathrm{D}-U a B L 98 \mathrm{VR} 4 \mathrm{WgM}: \& \mathrm{spf}=1522590818928}$ )

It was first described as a cause of human disease in 1985, with about ten species identified, out of which at least seven can infect humans, and the most important to the food industry is Trichinellaspiralis (Lawley, et al., 2012). Other species recognizedthat can infect humans include $T$. britovi, T. pseudospiralis, $T$. nativa, T. papuae T. murrelli, and T. nelsoni (Sterling, 2006).

\section{Occurrence in foods}

Domestic pigs are the most significant source of human infection worldwide. Additionally, infected meats from wild boars and horses have also played an important role in the outbreaks within the past decades (Gottstein, et al., 2009). In the EU and North America, infected pork from pigs was the main source of Trichinella infections, although effective controls in pork productions have reduced the prevalence of infection in commercial herds (Lawley, et al., 2012). Cysts of $T$. Spiralisoccur in large numbers in the diaphragm and tongue, as well as the skeletal muscles of the infected animal (Lawley, et al., 2012).

In human, the occurrence of Trichinellosis(a disease caused by $T$. spiralis) is firmly related to cultural practices in food consumption which include consumption of raw or undercooked meat (Dorny, et al., 2009).

\section{Route of infection}

The commonest route of infection of this parasite in humans was reported to be through consumption of raw or undercooked meat from an infected pig. The entire lifecycle occurs within a single host species which consists of an adult worm and other two larval stages. Human beings are not definitive hosts of this parasite but may be infected through ingestion of an infective larva in the striated muscle tissue of the infected animal during the second stage of the life cycle as shown in the Figure below (Dorny, 2009; Lawley, et al., 2012). 


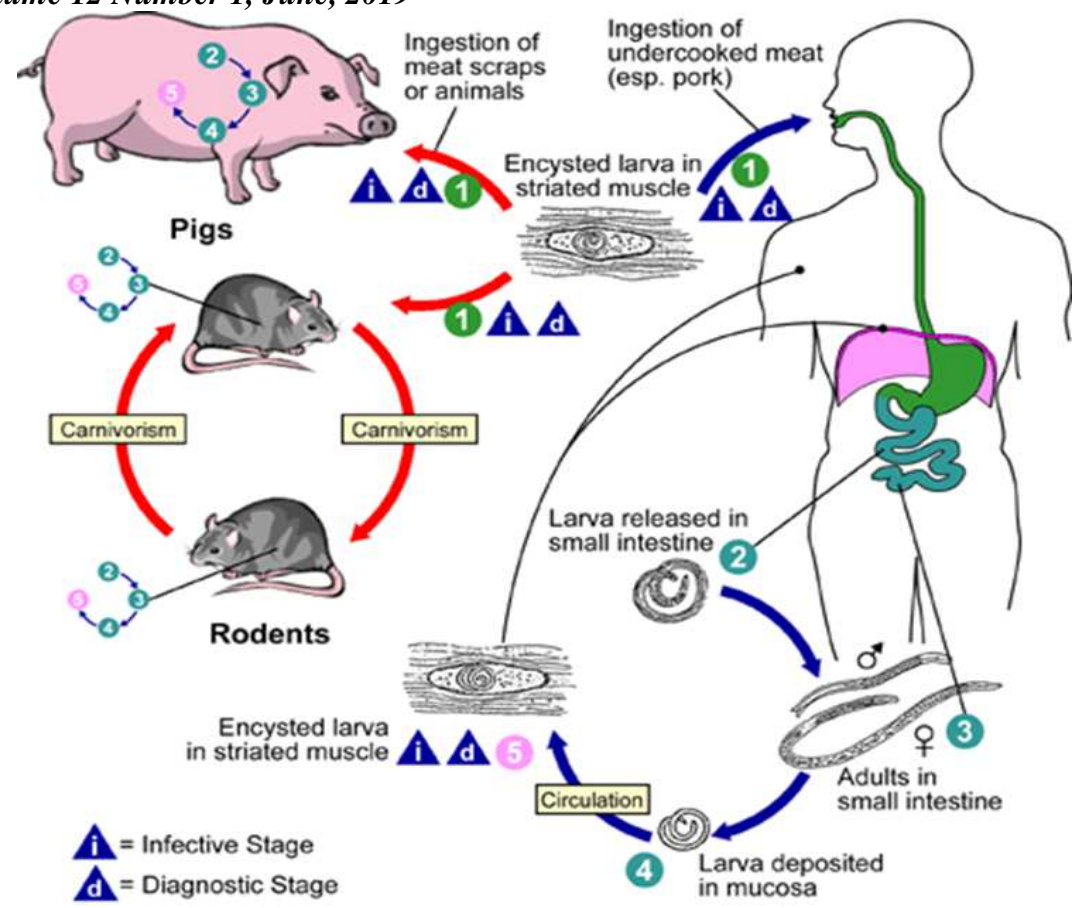

Figure 4 Life Cycle of Trichinellosis

Source: (https://www.cdc.gov/parasites/trichinellosis/biology.html).

\section{Symptoms}

There is variability in humans on the severity of symptoms due to Trichinellosis infection and have reported being asymptomatic in some cases, while in others, infections may prove fatal. This is dependent on the specie of the parasite involved, the number of the cysts ingested and the strength of the immune response of an infected individual (Gottstein et al., 2009; Dorny, et al., 2009). Infective dose is said to be uncertain but has been estimated to be between 100 and 300 larvae (Lawley, et al., 2009). Typical symptoms include abdominal pain, diarrhea and vomiting with an onset period of 24-48h after ingestion and it may lead to other symptoms such as swelling of the face, muscle pain, and Conjunctivitis. In pregnant women, it can cause abortion or premature delivery while in children, symptoms are the same as those found in adults with less frequent diarrhea and myalgia (Dupouy-camet, et al., 2002). In few cases, there is an occurrence of complicated cardiovascular and/or neurological disorder with symptoms such as headache, apathy, chest pain, dizziness, and irregular heartbeat and may be fatal, particularly in elderly people (Lawley, et al., 2012).

\section{Incidence and outbreaks}

Over 11 million people in the world could be affected by Trichinellosis, with an annual estimate of about 10, 000 cases and the mortality rate is said to $0.2 \%$ (Pozio, 2007). In the EU and North America, the incidence has declined over the years with only 11 cases being reported between 2002 and 2007. This is due to control measures that are being put in place to prevent the spread of the infection as contained in the EU Regulation (EC No 2075/2005) on official controls for Trichinella in meat which provides regulation for the control of Trichinellosisby inspection at slaughter, using detection methods and suitable freezing procedures (Lawley, et al., 2012).

\section{Stability in foods and control measures}

The cysts of Trichinella are very persistent in its live host and can survive many years in a striated muscle tissue. However, it is not resistant to freezing, andis killed rapidly at $21^{\circ} \mathrm{C}$. They are destroyed rapidly by temperatures greater than $66^{\circ} \mathrm{C}$ and can be killed with boiling water (Carme,et al., 2009). Other control measures include inspection at slaughter and the use of detection methods as provided in the EC regulation 2075/2005 on official controls for Trichinellain meat (Lawley, et al., 2012). Toxoplasmagondii oocysts are resistant to most disinfectants, but they can be inactivated by formalin and ammonia. They are destroyed rapidly by temperatures greater than $66^{\circ} \mathrm{C}\left(151^{\circ} \mathrm{F}\right)$ and can be killed with boiling water. Tincture of iodine (2\%) can inactivate Toxoplasmagondii with a long exposure time of at least 3 hours (CSFPH and IICAB, 2017). 
BAJOPAS Volume 12 Number 1, June, 2019 Treatment

Prompt treatment with antiparasitic drugs can help prevent the progression of Trichinellosis by killing the adult worms and so preventing further release of the larvae (Dupouy-camet, et al., 2002). The medical treatment for this disease includes anthelmintics (mebendazole or albendazole), glucocorticosteroids and preparations that compensate for protein and electrolyte deficits(Gottstein, et al., 2009). For complete and effective treatment of
Trichinellosis, anthelmintics must act against the parasite at all stages of development in various parts of the body (Dupouy-camet, et al., 2002). Steroids used in combination with mebendazole will shorten the duration of fever in a person infected with trichinellosis (Klein, et al., 1980). The recommended dose for albendazole is 400 mg twice daily for 8 to 14 days; for mebendazole, it is 200 to $400 \mathrm{mg}$ three times a day for 3 days, followed by 400 to $500 \mathrm{mg}$ three times a day for 10 days (Gottstein, et al., 2009).

Table 2. Practical recommendations to handle clinical Trichinellosis cases

\section{Severity \\ Treatment}

Severe and moderately severe diseases

Benign, abortive, and asymptomatic diseases
- Hospitalization is compulsory for severe forms and debatable for moderately severe forms.

- Administration of anthelmintics (albendazole or mebendazole).

- Monitoring of the pharmacokinetics of anthelmintics (if possible).

- Administration of glucocorticosteroids (eg., prednisolone) always with anthelmintics.

- Compensation of fluids and electrolyte deficits.

- Administration of pain killers.

- Administration of anthelmintics (albendazole or mebendazole).

- Administration of nonsteroidal antiinflammatory drugs if necessary.
Source:(Gottstein, et al., 2009)

\section{CONCLUSION}

The rising concern over food safety and food security by the consumers has led to more attention given to the control of foodborne parasitic infections. Nevertheless, the systems being used for routine diagnosis, reporting, and monitoring of foodborne parasites has been grossly insufficient or even non-existing. As a result, there has been an underestimation of human diseases and occurrence of parasites in foods, coupled with the asymptomatic nature of most of the parasitic illnesses, and the difficulty in diagnosing it in humans (Dorny, et al., 2009).

\section{RECOMMENDATION}

It is recommended that to achieve a better monitoring and control of parasitic foodborne

\section{REFERENCES}

Antoniou, M., Tzouvali, H., Sifakis, S., Galanakis, E., Georgopoulou, E. and Tselentis, Y. (2007). Toxoplasmosis in pregnant women in Crete. Journal of Parasitology 49, 231-233.

Affected, S., Distribution, G., \& Cycle, L. (2017). Toxoplasmosis, (January), 1-13. infections, new risk assessment tools should be used, in addition to an effective monitoring and control of water and food, through proper utilization of new technologies such as molecular and serological methods, health education, economic development, and vaccination. Good hygienic practices in the farms, inspection at slaughter, and use of detection methods, heat treatments and other prerequisite programmes in meat production are strongly recommended. Water supply systems should be controlled and monitored to avoid food contamination with the parasites. These measures should be more stringent on the food that is consumed raw or undercooked, like fruits, vegetables, and shellfish.

Bojar I. and Szymanska J. Environmental exposure of pregnant women to infection with Toxoplasma gondii-state of the art. Ann Agric Environ Med (2010);17:209- 14.

Boucher, M., Qc, M., Ogilvie, G., \& Bc, V. (2013). Toxoplasmosis in Pregnancy:, (285), 17. 
BAJOPAS Volume 12 Number 1, June, 2019

Carme, B., Demar, M., Ajzenberg, D., \&Dardé, M. L. (2009). Severe Acquired Toxoplasmosis Caused by Wild Cycle of, 15(4). https://doi.org/10.3201/eid1504.081306

Cavalcante, G.T., Aguilar, D.M., Camargo, L.M., Labruna, M.B., de Andrade, H.F., Meireles, L.R., Dubey, J.P., Thulliez, P., Dias, R.A. and Gennari, S.M. (2006). Seroprevalence of Toxoplasma gondii antibodies in humans from rural Western Amazon, Brazil. Journal of Parasitology 92, 647-649.

Centre for Disease Control and Prevention. (2017). Parasites: Trichinellosis. Available from: http://www.cdc.gov/parasites/trichinello sis/biology.html(accessed 4 December 2017)

Centre for Disease Control and Prevention (2018). About Parasites. Available from: https://www.cdc.gov/parasites/about.ht ml(accessed 2 January 2018).

Center for Food Security and Public Health and Institute for International Cooperation in Animal Biologics (2017).Toxoplasmosis; Toxoplasma Infection.

Dorny, P., Praet, N., Deckers, N. and Gabriel, S. (2009). Emerging food-borne parasites. Veterinary Parasitology 169, 196-206.

Dubey, J. P. (1997). Survival of Toxoplasma gondii tissue cysts in $0.85-6 \% \mathrm{NaCl}$ solutions at 4-208 C. J. Parasitol. 83:946-949.

Dupouy-camet, J., Kociecka, W., Bruschi, F., Bolas-, F., \&Pozio, E. (2002). Opinion on the diagnosis and treatment of human trichinellosis, 1117-1130.

European Food Safety Agency (2017).Parasites in foods. Available from: http://www.efsa.europa.eu/en/topics/to pic/parasitesinfood.htm (assessed 26 November 2017).

Gottstein, B., Pozio, E. and No" ckler, K. (2009).Epidemiology, diagnosis, treatment, and control of trichinellosis. Clinical Microbiology Reviews 22, 127145.

Han, K., Shin, D.W., Lee, T.Y. and Lee, Y.H. (2018). Seroprevalence of Toxoplasma gondii infection and risk factors associated with seropositivity of pregnant women in Korea. Journal of Parasitology 94, 963965.https://www.vectorstock.com/royalt $\mathrm{y}$-free-vector/toxoplasma-gondii-vector11563382 (assessed on 14 January 2018) https://www.google.com.ng/search?q=partial+c oil+of+trichinella+larva\&tbm=isch\&tbo $=$ u\&source $=$ univ\&sa $=$ X\&ved $=0$ ahUKEwj x7t7jnJnaAhUC3iwKHUONAmgQsAQIJA\& biw $=1368 \&$ bih $=650$ \#imgrc $=$ DUaBL98vR4WgM:\&spf=1522590818928( assessed on 6 December 2017)

https://www.cdc.gov/parasites/trichinellosis/biol ogy.html (assessed on 12 January 2018)

https://www.vectorstock.com/royalty-freevector/toxoplasma-gondii-vector11563382 (assessed on 15 January 2018)

Jeffrey Jones, M.D., M.P.H., Adriana Lopez, M.H.S. and Marianna Wilson, M.S. (2003). Congenital Toxoplasmosis.American Family Physician 67, 2132.

Kijlstra, A., and Jongert, E. (2009). Toxoplasma-safe meat: close to reality? Trends in Parasitology 25, 18-22.

Klein, J., Zakharenco, DF.,Dolgina, LE., Braginetz, WR., and Linkola, WC. (1980). Etiotropic therapy and prophylaxis in trichinellosis.In Trichinellosis Proceedings of the $5^{\text {th }}$ International Conference on Trichinellosis. Kim, CW., Ruitenberg, EJ.,Teppema, JS (Eds), Reedbooks, Chertsey, UK. 291-296

Lawley, R., Curtis, L. and Davis, J. (2012). The Food Safety Hazard Guidebook. Pp. 163184. Cambridge, UK: The Royal Society of Chemistry.

Liu, Q., Wei, F., Gao, S., Jiang, L., Lian, H., Yuan, B., Yuan, Z., Xia, Z., Liu, B., Xu, X. and Zhu, X.Q. (2009). Toxoplasma gondii infection in pregnant women in China. Transactions of the Royal Society of Tropical Medicine and Hygiene 103, 162-166

Liu, Q., Singla, L. Das, \& Zhou, H. (2012). Vaccines against Toxoplasma gondii: Status, challenges and future directions. Human Vaccines \&Immunotherapeutics, 8(9), 1305-1308. https://doi.org/10.4161/hv.21006

Ortega, Y.R. (2006).Toxoplasmosis. In Foodborne Parasites ed. Ortega, Y.R. pp. 109-115, New York, USA: Springer Science Media.

Pozio, E. (2007).Taxonomy, biology and epidemiology of Trichinella parasites. In FAO/WHO/OIE Guidelines for the Surveillance, Management, Prevention and Control of Trichinellosised. DupouyCamet, J. and Murrell, K.D. pp. 1-35, Paris, France: OIE Publishers. 
BAJOPAS Volume 12 Number 1, June, 2019

Pozio, E. and Murrell, K.D. (2006). Systematics and epidemiology of Trichinella. Advances in Parasitology 63, 367-439.

Robertson, L.J. (2007). The potential for marine bivalve shellfish to act as transmission vehicles for outbreaks of protozoan infections in humans: a review. International Journal of Food Microbiology 120, 201-216.

Saadatnia, G., \&Golkar, M. (2012).A review on human toxoplasmosis. Scandinavian Journal of Infectious Diseases, 44(11), 805-814.

https://doi.org/10.3109/00365548.2012. $\underline{693197}$

Sterling, C.R. (2006). Foodborne nematode infections. In Foodborne Parasites ed. Ortega, Y.R. pp. 135-143, New York, USA: Springer Science Media.

Tenter, A.M., Heckeroth, A.R., Weiss, L.M. (2000) Toxoplasma gondii: from animals to humans. International Journal of Parasitology 30, 1217-1258.

The European Foundations Initiative for African Research into Neglected Tropical
Diseases. (2013). Neglected Tropical Diseases Initiative. Available from: (http://ntd-africa.net/) (accessed 26 November 2017).

USDA (2017).Parasites and Foodborne Illness. Available from: http://www.fsis.usda.gov/wps/portal/fsis /topics/food-safety-education/getanswers/food-safety-factsheets/foodborne-illness-anddisease/parasites-and-foodborne-illness/ (accessed 4 November 2017).

WHO (2010).Working to overcome the global impact of neglected tropical diseases. Available from: http://whqlibdoc.who.int/publications/20 10/9789241564090 eng.pdf (assessed 20 November 2017).

WHO (2015).Estimates of the Global Burden of Foodborne Diseases.Toxoplasmosis Factsheet.Available from http://www.euro.who.int/_data/assets/ pdf file/0011/294599/FactsheetToxoplasmosis-en.pdf. (assessed on 12 January 2018) 